Vol. 1 No. 2, Juni 2021, hlm. $121-126$

DOI: https://doi.org/10.33330/jutsi.v2i1.1149

Available online at http://jurnal.stmikroyal.ac.id/index.php/jutsi

\title{
IMPLEMENTASI E-KGB PNS PADA PEMERINTAH KABUPATEN ASAHAN (STUDI BKD KABUPATEN ASAHAN)
}

\author{
Juliani $^{1}$, Bachtiar Efendi ${ }^{2^{*}}$, Rika Nofitri ${ }^{2}$ \\ ${ }^{1}$ Mahasiswa Prodi Sistem Informasi, STMIK Royal \\ ${ }^{2}$ Prodi Sistem Komputer, STMIK Royal \\ *email: youngthady@gmail.com
}

\begin{abstract}
Periodic salary increases are very important given to Civil Servants who have reached the group working period, which is every two years and if they have fulfilled the requirements based on laws and regulations. Regional Personnel Agency of Asahan Regency still uses word processing software, such as Microsoft Office Word to process decree of periodic salary increase. This allows delays to generate of decrees and periodic salary increases reports. In this research using UML as a system modeling language, MySQL as a database, and PHP as a programming language. The results of this research are electronic applications of periodic salary increases that can be used by staffing Information and Documentation staff easily and more efficiently to generate decrees and periodic salary increase reports. Whereas the Civil Servants can input data and upload requirement for periodic salary increases without the need to come to the Regional Personnel Agency of Asahan Regency.
\end{abstract}

Keywords: Periodic Salary Increases; Electronic Application; MySQL; PHP

\begin{abstract}
Abstrak: Kenaikan gaji berkala sangat penting diberikan kepada Pegawai Negeri Sipil (PNS) yang telah mencapai masa kerja golongan yaitu setiap dua tahun sekali dan apabila telah memenuhi persyaratan berdasarkan peraturan perundang - undangan. Badan Kepegawaian Daerah (BKD) Kabupaten Asahan masih menggunakan software pengolah kata, seperti Microsoft Office Word untuk proses surat keputusan kenaikan gaji berkala. Hal ini memungkinkan terjadinya keterlambatan untuk menghasilkan surat keputusan dan laporan kenaikan gaji berkala. Dalam penelitian ini menggunakan UML sebagai bahasa pemodelan sistem, MySQL sebagai database, dan PHP sebagai bahasa pemrogramannya. Hasil dari penelitian ini adalah aplikasi elektronik kenaikan gaji berkala (E-KGB) yang dapat digunakan oleh staf Informasi dan Dokumentasi Kepegawaian dengan mudah dan lebih efisiensi untuk menghasilkan surat keputusan dan laporan kenaikan gaji berkala. Sedangkan Pegawai Negeri Sipil dapat melakukan input data dan upload syarat kenaikan gaji berkala tanpa perlu datang ke Badan Kepegawaian Daerah (BKD) Kabupaten Asahan.
\end{abstract}

Kata kunci: Kenaikan Gaji Berkala; Aplikasi Elektronik; MySQL; PHP

\section{PENDAHULUAN}

Badan Kepegawaian Daerah (BKD) Kabupaten Asahan merupakan perangkat pemerintah mempunyai tugas dan fungsi serta bertanggung jawab membantu Kepala Daerah melalui Sekretaris Daerah berdasarkan perundang-undangan dibidang kepegaw- 
Vol. 1 No. 2, Juni 2021, hlm. $121-126$

DOI: https://doi.org/10.33330/jutsi.v2i1.1149

Available online at http://jurnal.stmikroyal.ac.id/index.php/jutsi

aian dalam melaksanakan manajemen dan administrasi Pegawai Negeri Sipil (PNS) di lingkungan Pemerintah Kabupaten Asahan agar lebih terarah sesuai dengan kebijaksanaan yang telah ditetapkan Bupati. Pelaksanaan administrasi yang sering dilakukan Badan Kepegawaian Daerah (BKD) Kabupaten Asahan salah satu diantaranya adalah pembuatan surat keputusan kenaikan gaji berkala.

Kenaikan gaji berkala atau disingkat KGB merupakan salah satu program pemerintah dalam menaikkan gaji untuk meningkatkan daya dan hasil guna serta kesejahteraan PNS yang telah mencapai masa kerja golongan yaitu setiap dua tahun sekali dan telah memenuhi persyaratan sesuai perundang-undangan yang berlaku [1]. Kenaikan gaji berkala harus diberikan tepat waktu karena pegawai telah bekerja dan memberikan waktu, pikiran dan tenaga serta keterampilannya kepada organisasi untuk mencapai tujuan organisasi tersebut. PNS berhak memperoleh gaji yang adil dan layak sesuai beban pekerjaan dan tanggung jawabnya.

Dapat dibayangkan betapa kurang efektif dan efisien pembuatan surat kenaikan gaji berkala yang masih dilakukan secara manual dengan diketik satu-persatu dan berulang-ulang melalui software pengolah kata dan disimpan di komputer staf informasi dan dokumentasi kepegawaian. Sehingga memungkinkan terjadinya kesalahan pada surat kenaikan gaji berkala dan adanya surat yang hilang ketika terjadi permasalahan pada komputer tersebut.

Mengingat banyaknya jumlah PNS di lingkungan pemerintah Kabupaten Asahan yang harus ditangani oleh BKD Kabupaten Asahan membuat kenaikan gaji berkala sering terjadi keterlambatan. Faktor penyebabnya dikarenakan sulit mencari data PNS dan memakan waktu pekerjaan di bidang informasi dan dokumentasi kepegawaian yang memiliki tugas mengumpulkan, menghimpun, dan mengolah data. Selain itu, jarak tempuh yang jauh antara unit kerja PNS ke BKD Kabupaten Asahan membuat pegawai terlambat menyerahkan syarat-syarat yang dibutuhkan untuk pengusulan kenaikan gaji berkala. Kesalahan dan keterlambatan dapat menyebabkan kerugian bagi pegawai maupun instansi itu sendiri.

Berkaitan dengan hal tersebut, tujuan penelitian ini untuk menghasilkan suatu aplikasi berbasis web atau elektronik kenaikan gaji berkala (E-KGB) yang berfungsi membantu peningkatan efisiensi waktu dan menghindari kesalahan data PNS pengusul kenaikan gaji berkala pada BKD Kabupaten Asahan [2]. E-application disebut juga web merupakan sebuah software yang berfungsi untuk menampilkan dokumen dan dapat diakses pengguna melalui koneksi internet dan antarmuka browser [3]. E-KGB adalah mekanisme proses usulan kenaikan gaji berkala PNS yang dilakukan secara terintegrasi menggunakan aplikasi yang bisa diakses secara online. Sistem online memberikan fasilitas bagi PNS untuk menerima maupun mengakses informasi dimanapun mereka berada [4].

\section{METODE}

Metode penelitian yang digunakan adalah metode analisis dengan pendekatan terstruktur yang lengkap dengan alat (tools) dan teknik yang dibutuhkan dalam sistem sehingga hasil analisis dari sistem yang dikembangkan menghasilkan sistem yang strukturnya dapat didefinisikan dengan baik dan jelas. 
Vol. 1 No. 2, Juni 2021, hlm. $121-126$

DOI: https://doi.org/10.33330/jutsi.v2i1.1149

Available online at http://jurnal.stmikroyal.ac.id/index.php/jutsi

Adapun teknik pengumpulan data yang dipergunakan dalam penelitian ini adalah: (1) Wawancara (Interview), Wawancara dilakukan kepada ibu Vera Ningsih Siahaan. S.Si, M.Si selaku Kepala Sub Bidang Informasi dan Dokumentasi. Wawancara digunakan untuk memperoleh data syarat-syarat kenaikan gaji berkala di BKD Kabupaten Asahan., (2) Observasi atau Pengamatan, Pengumpulan data dengan cara terjun langsung mengamati proses kenaikan gaji berkala di BKD Kabupaten Asahan di jalan Jenderal Sudirman nomor 5 Kisaran., (3) Dokumentasi, Mencari data mengenai hal-hal kenaikan gaji berkala di BKD Kabupaten Asahan yang berupa catatan buku, surat, agenda, dan lain sebagainya., (4) Studi Literatur, Metode pengumpulan data dan informasi melalui membaca buku-buku, jurnal, penelitian terdahulu, dan lain sebagainya yang berkaitan dengan penelitian yang sedang dilakukan.

Tabel 1. Jumlah PNS di Lingkungan Pemerintah Kabupaten Asahan

\begin{tabular}{|c|l|c|c|c|c|}
\hline \multirow{2}{*}{ No } & Tingkat Kepangkatan dan & \multicolumn{5}{|c|}{ Tahun } \\
\cline { 3 - 6 } & & $\mathbf{2 0 1 6}$ & $\mathbf{2 0 1 7}$ & $\mathbf{2 0 1 8}$ & $\mathbf{2 0 1 9}$ \\
\hline 1 & I/A (Juru Muda) & 25 & 6 & 4 & 2 \\
\hline 2 & I/B (Juru Muda Tingkat I) & 19 & 8 & 5 & 5 \\
\hline 3 & I/C (Juru) & 32 & 38 & 34 & 26 \\
\hline 4 & I/D (Juru Tingkat I) & 22 & 17 & 11 & 14 \\
\hline 5 & II/A (Pengatur Muda) & 273 & 230 & 171 & 179 \\
\hline 6 & II/B (Pengatur Muda Tingkat I) & 290 & 218 & 144 & 142 \\
\hline 7 & II/C (Pengatur) & 435 & 652 & 656 & 664 \\
\hline 8 & II/D (Pengatur Tingkat I) & 304 & 292 & 266 & 268 \\
\hline 9 & III/A (Penata Muda) & 903 & 864 & 730 & 793 \\
\hline 10 & III/B (Penata Muda Tingkat I) & 717 & 740 & 713 & 891 \\
\hline 11 & III/C (Penata) & 683 & 714 & 757 & 784 \\
\hline 12 & III/D (Penata Tingkat I) & 1.081 & 1.093 & 1.084 & 1.064 \\
\hline 13 & IV/A (Pembina) & 2.381 & 2.031 & 1.696 & 1.449 \\
\hline 14 & IV/B (Pembina Tingkat I) & 150 & 233 & 455 & 560 \\
\hline 15 & IV/C (Pembina Utama Muda) & 32 & 34 & 37 & 40 \\
\hline 16 & IV/D (Pembina Utama Madya) & 4 & 4 & 3 & 3 \\
\hline 17 & IV/E (Pembina Utama) & - & - & - & - \\
\hline & Jumlah & $\mathbf{7 . 3 5 1}$ & $\mathbf{7 . 1 7 4}$ & $\mathbf{6 . 7 6 6}$ & $\mathbf{6 . 8 8 4}$ \\
\hline
\end{tabular}

(Sumber : Badan Kepegawaian Daerah Kabupaten Asahan)

Tabel 2. Syarat-Syarat Kenaikan Gaji Berkala

\begin{tabular}{|c|l|}
\hline No & \multicolumn{1}{|c|}{ Keterangan } \\
\hline 1 & Surat pengantar dari unit kerja (1 lembar) \\
\hline 2 & Fotocopy surat keputusan pangkat terakhir (1 lembar) \\
\hline 3 & Fotocopy surat keputusan kenaikan gaji berkala terakhir (1 lembar) \\
\hline
\end{tabular}

(Sumber : Badan Kepegawaian Daerah Kabupaten Asahan)

Syarat yang diajukan oleh PNS menjadi ketentuan penting dalam menindaklanjuti proses pembuatan surat keputusan kenaikan gaji berkala yang baru. Jika salah satu syarat tidak lengkap, maka staff menunggu kelengkapan syarat dari PNS. Sedangkan 
Vol. 1 No. 2, Juni 2021, hlm. $121-126$

DOI: https://doi.org/10.33330/jutsi.v2i1.1149

Available online at http://jurnal.stmikroyal.ac.id/index.php/jutsi

untuk besaran gaji pokok PNS sesuai dengan Peraturan Pemerintah Republik Indonesia Nomor 15 Tahun 2019 [5].

\section{HASIL DAN PEMBAHASAN}

Berikut ini merupakan implementasi antarmuka dari aplikasi elektronik kenaikan gaji berkala (E-KGB) PNS di Lingkungan Pemerintah Kabupaten Asahan pada BKD Kabupaten Asahan.

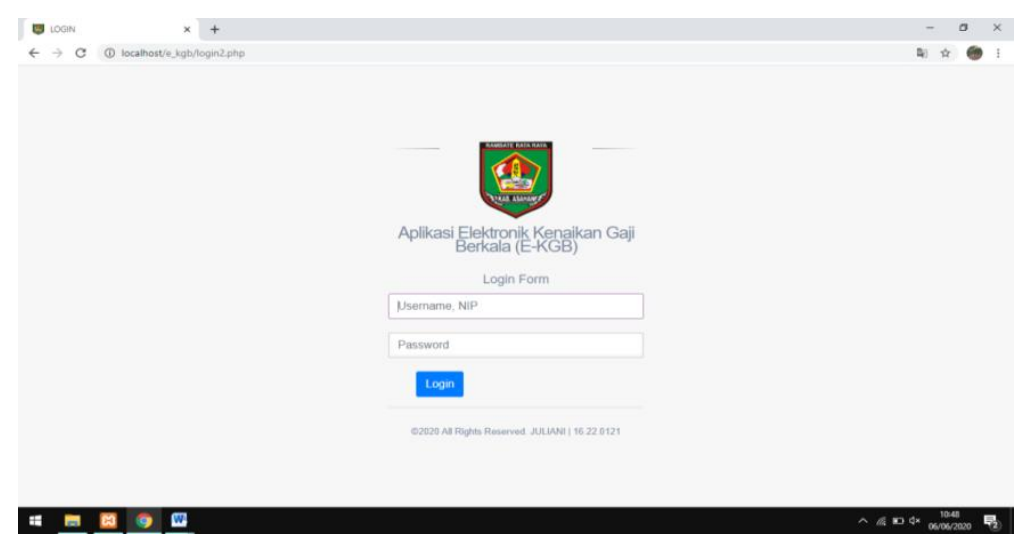

Gambar 1. Tampilan Login

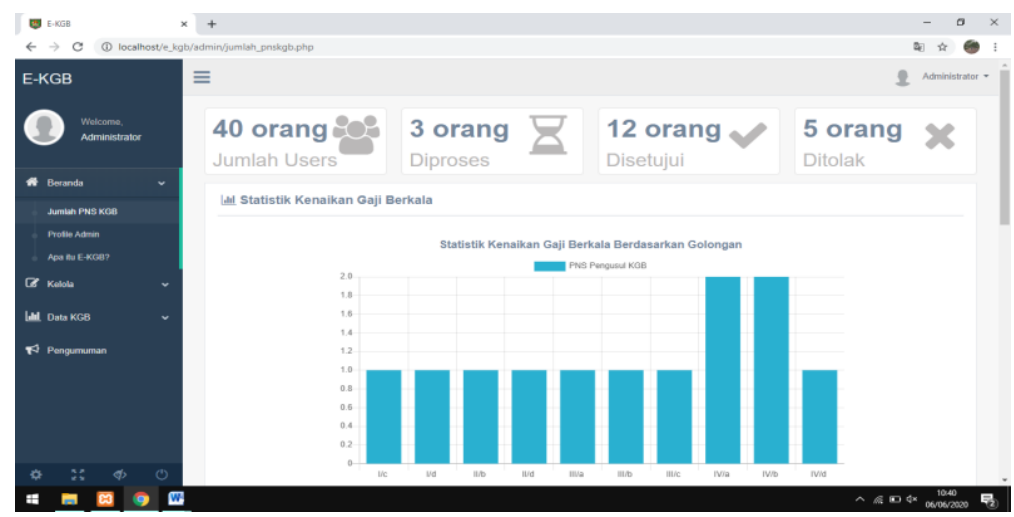

Gambar 2. Tampilan Beranda Admin

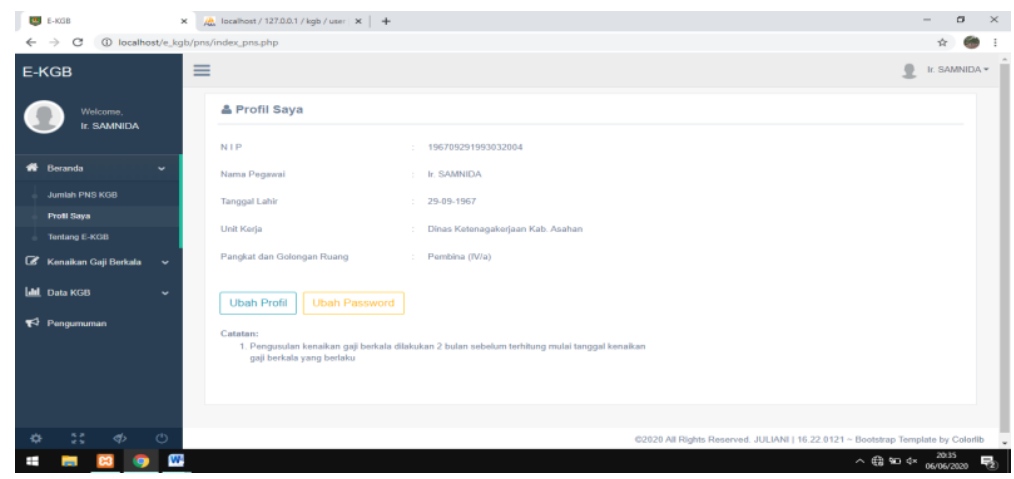

Gambar 3. Tampilan Profil PNS 
Vol. 1 No. 2, Juni 2021, hlm. $121-126$

DOI: https://doi.org/10.33330/jutsi.v2i1.1149

Available online at http://jurnal.stmikroyal.ac.id/index.php/jutsi

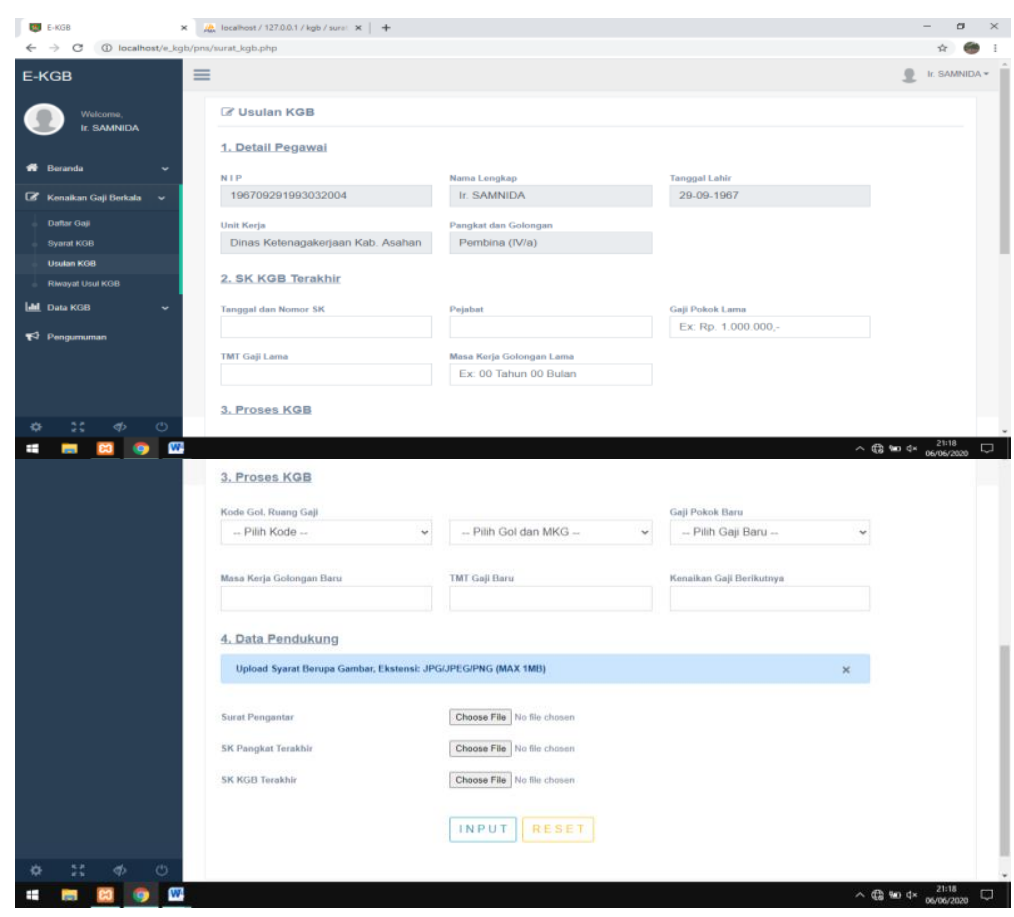

Gambar 4. Tampilan Usul KGB

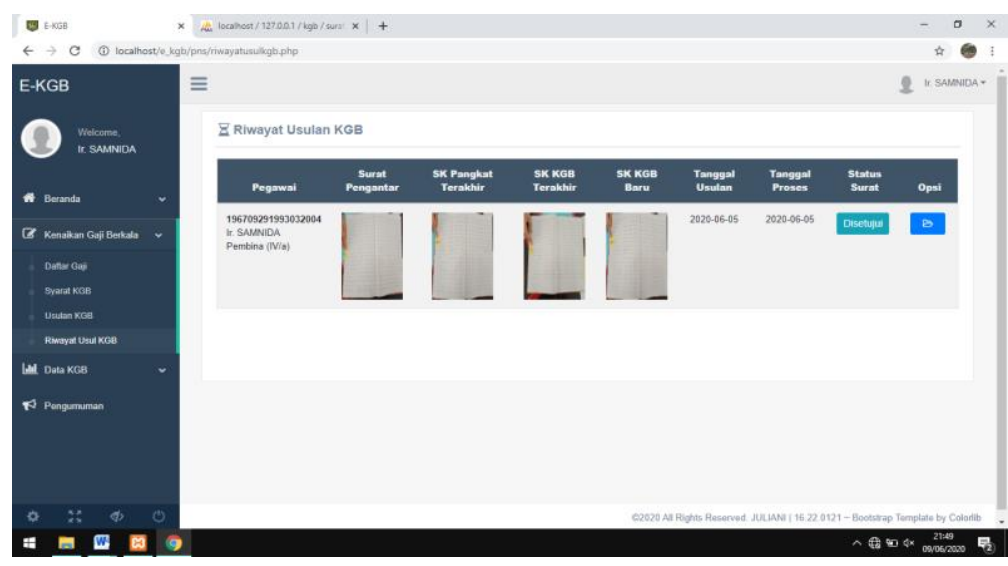

Gambar 5. Tampilan Riwayat Usul KGB

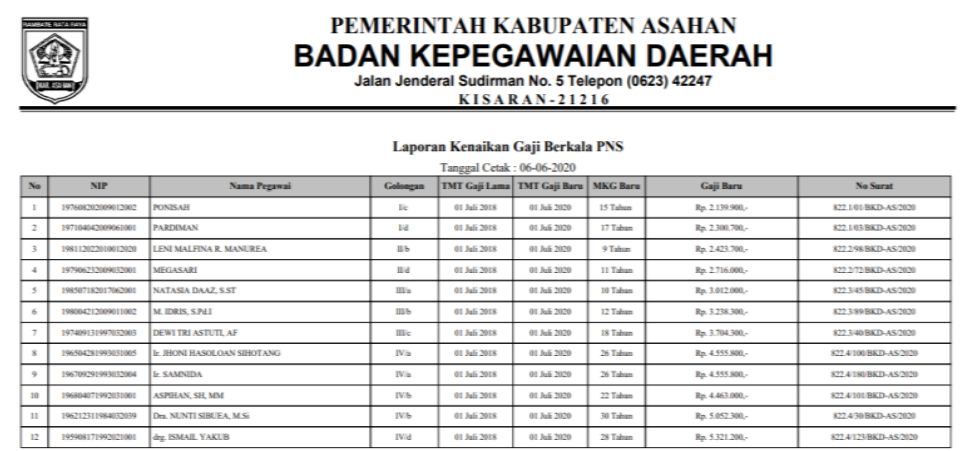

Gambar 7. Tampilan Laporan KGB 
Vol. 1 No. 2, Juni 2021, hlm. $121-126$

DOI: https://doi.org/10.33330/jutsi.v2i1.1149

Available online at http://jurnal.stmikroyal.ac.id/index.php/jutsi

\section{SIMPULAN}

Berdasarkan penelitian yang telah dilakukan Penulis selama membuat aplikasi E-KGB ini, maka dapat diambil kesimpulan bahwa aplikasi ini dapat membantu staff pelaksana (admin) dalam meningkatkan efisiensi waktu pengelolaan kenaikan gaji berkala, sehingga menghasilkan surat keputusan dan laporan kenaikan gaji berkala PNS di lingkungan Pemerintah Kabupaten Asahan. Dengan menggunakan aplikasi ini PNS dapat dengan mudah melakukan pengusulan kenaikan gaji berkala tanpa perlu datang ke Badan Kepegawaian Daerah (BKD) Kabupaten Asahan, PNS dapat melakukan input data dan upload syarat usulan kenaikan gaji berkala.

\section{DAFTAR PUSTAKA}

[1] F. Kurnia and N. Putri, "Sistem Informasi Cuti Tahunan Pegawai Dinas Sosial Provinsi Riau,” J. Ilm. Rekayasa dan Manaj. Sist. Inf., vol. 6, no. 2, pp. 186-191, 2020.

[2] I. Eviana, Lisnawanty, and D. O. Sihombing, "Aplikasi Administrasi Kenaikan Gaji Berkala Berbasis Web pada Badan Penanggulangan Bencana Daerah Provinsi Kalimantan Barat," J. Khatulistiwa Inform., vol. V, no. 1, pp. 21-29, 2017, [Online].

[3] M. Destiningrum and Q. J. Adrian, "Sistem Informasi Penjadwalan Dokter Berbassis Web Dengan Menggunakan Framework Codeigniter (Studi Kasus: Rumah Sakit Yukum Medical Centre)," J. Teknoinfo, vol. 11, no. 2, p. 30, 2017, doi: 10.33365/jti.v11i2.24.

[4] Y. Elva, "Perancangan sistem Informasi Kepegawaian Berbasis WEB Pada Badan Kepegawaian Daerah ( BKD ) Dengan Menggunakan Bahasa Scripting PHP dan Database MySQL," J. Teknol., no. 1, pp. 20-26, 2016.

[5] P. Putusan and M. Konstitusi, "Tanggung jawab," no. November 2020, pp. 212220, 2018. 